\section{Rare day to highlight rare diseases}

In the last leap year in 2008, 29 February was chosen to mark Rare Disease Day by EURORDIS, the European Organisation for Rare Diseases. This year, this rare day will again serve to raise awareness of the plight of patients with rare disorders.

Rare diseases fail to attract commercial research efforts because of the small number of people affected (fewer than 5 in 10,000). Examples include the nerve disorder Charcot-MarieTooth disease and Proteus syndrome, which causes excess overgrowth of tissues.

As a result, only a handful of scientists, often working in isolation, dedicate their research to a particular rare disease. But such select studies can deliver groundbreaking insights into more general disease processes. Exposure of molecular mechanisms underlying rare diseases therefore has the potential to help many other patients.

Also on 29 February, the first international congress dedicated to rare diseases will be held in Basel, Switzerland (www.react-congress.org). It will highlight the recently established International Rare Diseases Research Consortium (IRDiRC), which plans to coordinate international policy-making with results from national research projects. These initiatives should eventually translate scientific advances into benefits for patients.

Susan M. Gasser Friedrich Miescher Institute for Biomedical Research, Basel, Switzerland. susan.gasser@fmi.ch

James R. Lupski Baylor College of Medicine and Texas Children's Hospital, Houston, Texas, USA. Yann Le Cam European Organisation for Rare Diseases, Paris, France.

Olivier Menzel BLACKSWAN Foundation, Swiss Foundation for Research on Orphan Diseases, Porza, Switzerland.

\section{Asian medicine: small species at risk}

The demands of traditional Asian medicine (TAM) don't just pose a threat to the survival of tigers and rhinos (Nature 480, S101-S103; 2011). Numerous smaller species are also at risk, as a result of being traded in large volumes.

For example, millions of dried seahorses (Hippocampus spp.) and Tokay geckos (Gekko gecko) are sold annually for use against impotence and circulatory problems in TAM. Gecko sales have been further fuelled by rumours that larger individuals can cure HIV. Trade in dried orchid parts for eye ailments and in ginseng rhizomes is consuming plants in their millions. The decline in Asia's turtle population is being aggravated by the marketing of TAMs that contain turtle plastrons (the flat underbelly of the shell) to treat skin diseases.

The Convention on International Trade in Endangered Species seeks to protect most of these globally threatened species. The high demand for scaly anteaters, or pangolins (Manis spp.), for example, has led to an international trade ban. However, the scales of tens of thousands of pangolins are still confiscated annually in Asia.

For some species, captive breeding and plant propagation have been successful, but the demand for wild-sourced ingredients means that such techniques cannot wholly mitigate the impact of trade.

The killing of endangered tigers and rhinos for TAM will not go unnoticed. But the insidious destruction of smaller species must also be halted by enforcing stricter regulations. Vincent Nijman, K. AnneIsole Nekaris Oxford Brookes University, Oxford, UK. vnijman@brookes.ac.uk David P. Bickford National University of Singapore, Singapore.

\section{Call to split fisheries at home and abroad}

I agree that "no one should doubt that our seas need protection" (Nature 480, 151; 2011) and that establishing marine protected areas alone will not do the job (Nature 480, 14-15; 2011). A combination of measures is needed, including the elimination of overfishing subsidies. These incentives were introduced when fisheries seemed inexhaustible, but they inflate profitability and drive fishing beyond economic or sustainable levels.

The global community mandated the World Trade Organization (WTO) to discipline overfishing subsidies more than ten years ago, but the issues were still unresolved at their meeting last month. One reason is that WTO negotiators are trying to broker an all-inclusive deal that encompasses domestic and international, small- and largescale fisheries. But this approach is hindered by national interests.

The answer is to split the world's fisheries into domestic and international ones.

Domestic fisheries would operate within a country's economic exclusion zone and target fish stocks that spend all their lives there. This split is necessary because the incentives to eliminate overfishing subsidies differ according to whether a fishery is domestic or international.

For a domestic fishery, the heavy lifting should be on the home front; for an international fishery, global coordination would be needed, because unilateral action by one country will not eliminate overfishing. Categorizing fisheries in this way would make it easier to identify leverage points for eliminating overfishing subsidies.

U. Rashid Sumaila University of British Columbia, Vancouver, British Columbia, Canada. r.sumaila@fisheries.ubc.ca

\section{Investors unfazed by drug-patent expiry}

Your data on changing stock prices for five pharmaceutical companies from 1997 to 2010 (Nature 480, 16-17; 2011) erroneously indicate a 39\% drop in aggregated share value, when in fact it would have risen by $82 \%$ (see Correction, Nature 480, 425; 2011). The error was due mainly to the selection of unadjusted, rather than adjusted, stockmarket closing prices.

The corrected data set indicates that the aggregated share prices rose roughly in line with the Dow Jones Industry Average. Considering that these companies have the biggest patent cliffs in the industry, this result is very positive; moreover, it argues against your implication that the impending expiry of their patents is affecting investor confidence in pharmaceutical stocks.

Investors accept that the strength of a company's patent portfolio is only one of several factors. Hence, despite the impending expiry of patents for blockbuster products, including Pfizer's Lipitor, the performance of the five worst-hit companies was comparable with that of other sectors for the period 1997-2010.

Other factors such as decreasing revenues can also affect investor confidence. Your simplistic view that the patent cliff is the only contributor does an injustice to the efforts of pharmaceutical companies and governments, and unnecessarily perpetuates a false uncertainty.

David Brindley University College London, UK; Harvard Stem Cell Institute and Harvard Business School, Massachusetts, USA. david_brindley@harvard.edu Brock Reeve The Harvard Stem Cell Institute, Cambridge, Massachusetts, USA.

Chris Mason University College London, UK. 